\title{
Cross-screw technique for the modified Lapidus procedure using headless compression screws
}

\author{
Mayet $\mathrm{Z}^{1} \mathbb{0}$, Ferrao $\mathrm{PNF}^{2} \mathbb{C}$, Saragas $\mathrm{NP}^{3}$
}

1 BSc(Wits), MBChB(Medunsa), FC Orth (SA), MMed(Orth)(Wits); The Orthopaedic Foot and Ankle Unit, Netcare Linksfield Hospital, Johannesburg; Consultant, Chris Hani Baragwanath Academic Hospital and University of the Witwatersrand, Johannesburg, South Africa

2 MBChB(Pret), FCS(SA)Ortho; The Orthopaedic Foot and Ankle Unit, Netcare Linksfield Hospital, Johannesburg; Consultant, University of the Witwatersrand, Johannesburg, South Africa

3 MBBCh(Wits), FCS(SA)Ortho, MMed(Ortho Surg)(Wits); The Orthopaedic Foot and Ankle Unit, Netcare Linksfield Hospital, Johannesburg; Professor, University of the Witwatersrand, Johannesburg, South Africa

Corresponding author: Dr Ziyaad Mayet, PO Box 901177, Bertsham, 2013; tel: 011 4339522; fax: 0866013108; email: bonedoc.zm@gmail.com

\begin{abstract}
Aims: The aim was to evaluate union rates using two cross headless compression screws for the modified Lapidus procedure. This was compared to conventional fixation using solid $A O$ screws and plates, as recorded in the published literature.

Patients and methods: This is a retrospective study of the modified Lapidus procedure performed in patients with a moderate to severe hallux valgus deformity. Union time and patient demographics were retrieved from medical records. Patient demographics included age, sex, smoking habits and other comorbidities. The union rate was compared to the literature using the two-population probability test, with $p<0.05$ being significant.

Results: Sixty-nine feet in 56 patients were assessed for radiographic union. There were three delayed unions and two non-unions. The union rate of $97 \%$ was not statistically different when compared to studies using conventional solid AO screws.

Conclusion: The use of headless compression screws in the fixation of the first tarsometatarsal joint and early mobilisation was found to be comparable to conventional solid AO screws with regard to union rates. The cannulated design enhances ease of insertion and, being headless, minimises the risk of intra-operative fracture and hardware prominence requiring subsequent removal.
\end{abstract}

Level of evidence: Level 4

Key words: modified Lapidus, cross-screw technique, headless compression screw, hallux valgus, first ray instability

Citation: Mayet Z, Ferrao PNF, Saragas NP. Cross-screw technique for the modified Lapidus procedure using headless compression screws. SA Orthop J 2019;18(3):41-46. http://dx.doi.org/10.17159/2309-8309/2019/v18n3a4

Editor: $\operatorname{Dr} \mathrm{G}$ McCollum, University of Cape Town, Cape Town, South Africa

Received: January $2019 \quad$ Accepted: May $2019 \quad$ Published: August 2019

Copyright: ( 2019 Mayet Z, et al. This is an open-access article distributed under the terms of the Creative Commons Attribution Licence, which permits unrestricted use, distribution and reproduction in any medium, provided the original author and source are credited.

Funding: None.

Conflict of interest: None of the authors have any conflict of interest to declare. No benefits of any kind have been or are to be received from a commercial party related directly or indirectly to the subject of this article. 


\section{Introduction}

In 1934 Lapidus described a method of fusing the first tarsometatarsal joint for the treatment of hallux valgus. After preparation of the first tarsometatarsal and intermetatarsal joints, fixation was achieved by suturing the capsule with chromic catgut. ${ }^{1}$ A prolonged period of immobilisation followed. Lapidus reported non-union as one of his main complications.

Theories regarding the cause of hallux valgus has evolved in recent years, and the concept of first ray instability has become more important. ${ }^{2-9}$ Currently, the modified Lapidus procedure is seen as a very powerful procedure with the ability to correct deformities in three different planes simultaneously. ${ }^{2-9}$ The hallux valgus and metatarsus primus varus are corrected in the coronal plane; plantar angulation can be increased in the sagittal plane; and the pronation deformity is corrected in the axial plane. By correcting it at the source, the true cause of a hallux valgus deformity is therefore addressed..$^{9}$ Added to this, by arthrodesing the first tarsometatarsal joint, the likelihood of recurrence is reduced. However, Coetzee et al. have emphasised the need for proper surgical technique and attention to detail to minimise complications. ${ }^{10}$

The Lapidus procedure, over the years, has been criticised for several reasons. Most notable of these is a high non-union rate and prolonged post-operative immobilisation.,2,4 The technical difficulty of the procedure is one factor that contributes to this nonunion rate. Recent advances in fixation have resulted in an increase in the popularity of the procedure. Numerous reports have been published recently using solid screws or locking plates for fixation. Modern reviews quote the non-union rate at $2-10 \% .{ }^{3}$ However, a recent article reports it at $0-2.5 \% .^{2}$ Added to this, these publications also claim reduced times to weight bearing.

We present a technique for the modified Lapidus procedure using two $4.7 \mathrm{~mm}$ cannulated headless compression screws for fixation, as well as a retrospective review of our cases. The purpose of this retrospective review was to evaluate union rates using a cross-screw technique with two cannulated headless compression screws for fixation, and to compare this to union rates using other fixation techniques.

\section{Materials and methods}

\section{Study population and design}

A retrospective review was carried out of all patients that had undergone a modified Lapidus procedure using the cross-screw technique with two headless compression screws. The operations were performed by the senior authors (NPS and PNF) between February 2014 and March 2015. Exclusion criteria included: patients younger than 18 years, and absent data regarding status of bony union. Patient demographics included age, sex, smoking status and comorbidities. The indications for performing the modified Lapidus procedure included hypermobility of the first ray, severe hallux valgus deformities and recurrent hallux valgus deformities. Severity of the deformity was recorded as mild, moderate or severe. This was based on the hallux valgus (HV) angle and intermetatarsal (IM) angle, as shown in Table I. The data recorded from the operative notes included the side of operation, the addition of any other procedures to the hallux or the lesser toes, the use of bone graft and any complications intra-operatively or post-operatively. Lastly, the time to union was recorded. Follow-ups were done at one, two and four weeks for wound check and taping, and then at six weeks an $X$-ray was taken to assess for union. Union was defined as bridging of bone across three cortices, and non-union was defined as the lack of union at six months as described by De Vries et al. ${ }^{11}$ Delayed union was defined as any fusion that took place between six weeks
Table I: Classification of severity

\begin{tabular}{|l|c|c|c|c|}
\hline & $\begin{array}{c}\text { Hallux } \\
\text { valgus angle }\end{array}$ & $\begin{array}{c}\text { Intermetatarsal } \\
\text { angle }\end{array}$ & $\begin{array}{c}\text { Number } \\
\text { of feet (n) }\end{array}$ & $\mathbf{( \% )}$ \\
\hline Mild & $15-30^{\circ}$ & $9-15^{\circ}$ & 3 & 4 \\
\hline Moderate & $31-40^{\circ}$ & $16-20^{\circ}$ & 38 & 55 \\
\hline Severe & Above $40^{\circ}$ & Above $20^{\circ}$ & 19 & 28 \\
\hline Not classified & & & 4 & 6 \\
\hline Revisions & & & 5 & 7 \\
\hline Hypermobility & & & 44 & 64 \\
\hline
\end{tabular}

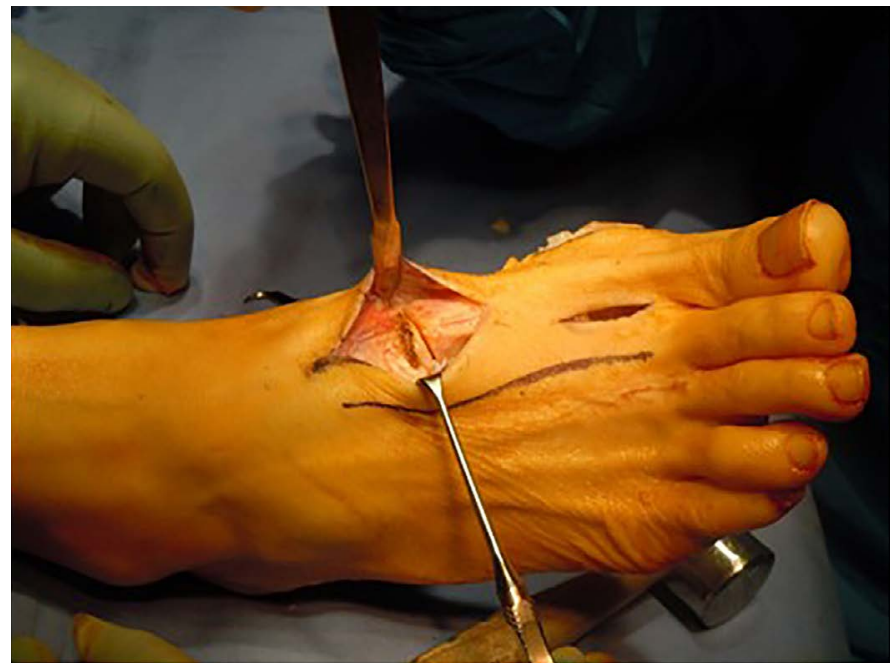

Figure 1. Completed osteotomies with second metatarsal orientation marking

and six months. Patients were then assessed at 12 weeks, as a final follow-up. Further assessments were scheduled as needed, especially in the cases of complications or non-unions.

\section{Operative technique}

A distal soft tissue release is performed first through a dorsal incision in the first web space. This includes sequential release of the adductor hallucis tendon, sesamoid suspensory ligament and the lateral capsule. This is followed by a bunionectomy through a medial skin incision and an L-shaped capsulotomy. The modified Lapidus procedure is then performed through a $3-4 \mathrm{~cm}$ incision dorsally over the first tarsometatarsal joint. The extensor hallucis longus tendon is retracted medially. A capsular incision is made, and the joint is carefully exposed. The proximal metatarsal articular surface is cut with an oscillating saw blade at the level of the subchondral plate. The orientation of the first metatarsal cut is perpendicular to the long axis of the first metatarsal in all planes. The medial cuneiform articular surface is then resected perpendicular to the long axis of the second metatarsal in the frontal and sagittal planes. By doing this the first metatarsal will be almost parallel to the second metatarsal once the fusion site is reduced, thus correcting the IM angle. A lamina spreader is very helpful in debriding the plantar surface and removing any remaining bony fragments. Figure 1 shows the skin marking over the long axis of the second metatarsal, as well as the perpendicular osteotomy made in the medial cuneiform. Both joint surfaces are then fenestrated using a $2.5 \mathrm{~mm}$ drill bit to allow for the access of marrow elements into the fusion site. The two joint surfaces are reduced, allowing for correction in all planes, with abduction and supination of the metatarsal. This is done while dorsiflexing the hallux, to ensure plantarflexion of the first metatarsal. The reduction is then secured with guide wires. The first guide wire is placed dorsolateral running from the medial cuneiform to the 


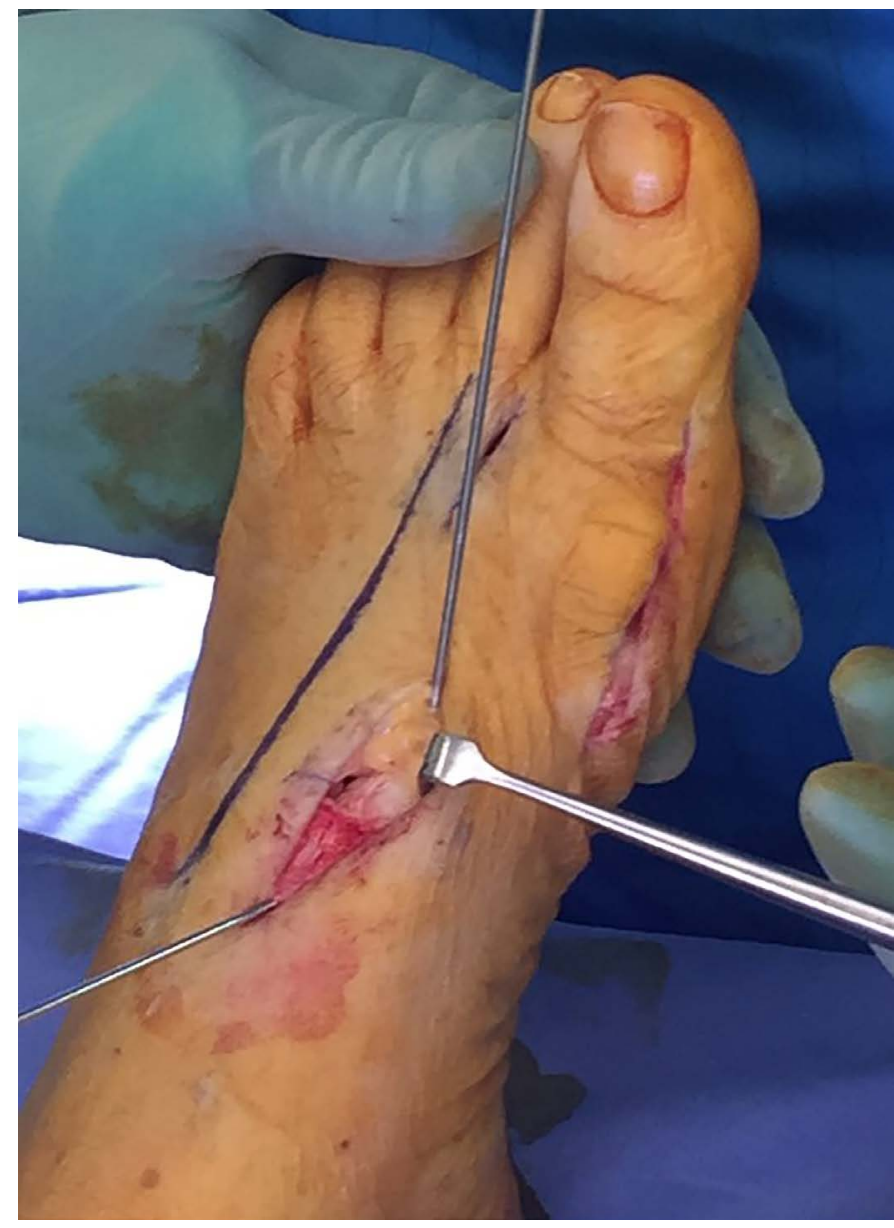

Figure 2. Placement of K-wires

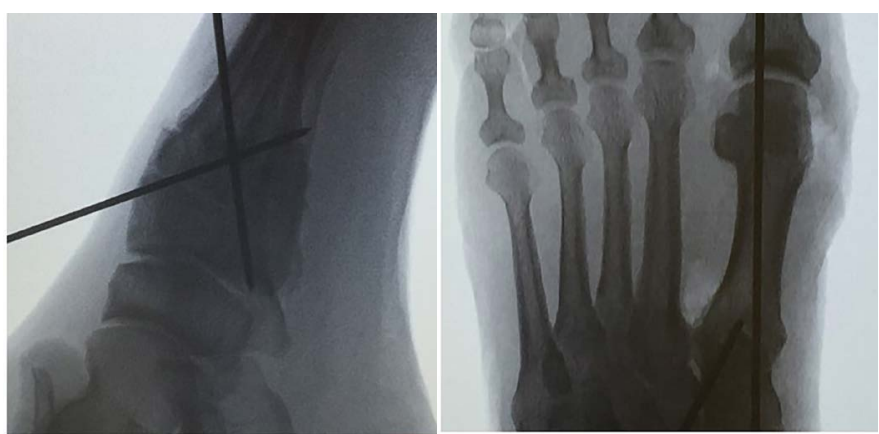

Figure 3. Image intensifier AP and lateral views confirming reduction and wire placement

plantar-lateral cortex of the first metatarsal. The second guide wire is placed dorsomedial on the first metatarsal running to the plantarmedial cortex of the medial cuneiform. Adequate correction of the $\mathrm{IM}$ angle and positioning of the guide wires is confirmed under image intensification. Figure 2 shows the placement of these wires, and Figure 3 shows their position under the image intensifier. The fusion site is then compressed and fixed using two $4.7 \mathrm{~mm}$ headless compression screws (Acutrak ${ }^{\circledR}$ Acumed, USA) (Figure 4). A distal medial closing wedge chevron osteotomy (MCWC) and Akin osteotomy are added when indicated. The MCWC is performed in cases with a high distal metatarsal articular angle (DMAA), which increases when doing a modified Lapidus (rotational correction). The Akin osteotomy is performed for correction of hallux valgus interphalangeus and pronation of the hallux. The capsule is repaired using Vicryl and the wound is closed in layers. The patient is placed in a heel-wedge shoe day 1 post surgery and taught to mobilise in it by the physiotherapist. The patient is advised to keep the foot

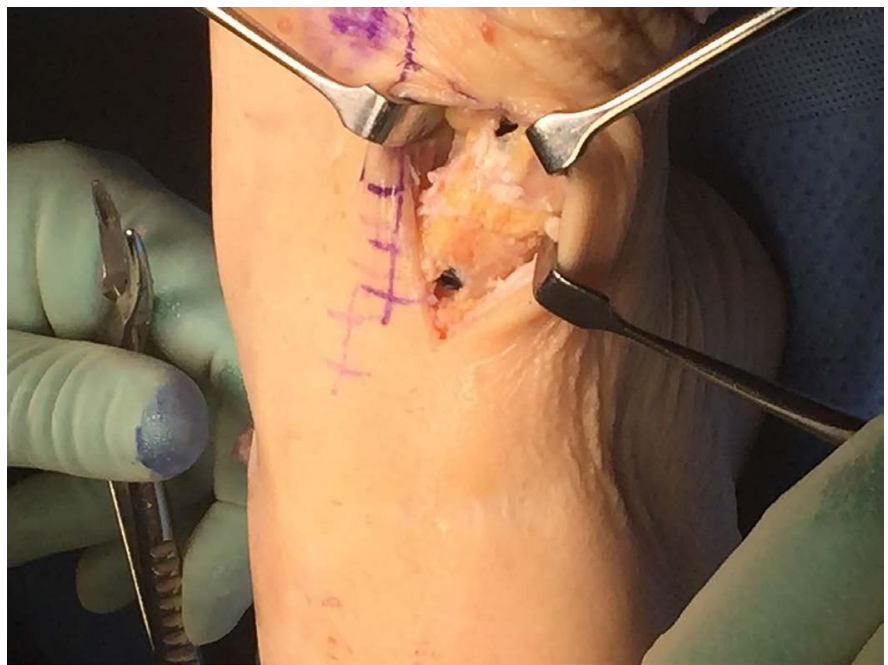

Figure 4. Compression across arthrodesis site after screw placement

elevated in the first two weeks. They can bear weight as tolerated in the heel-wedge shoe for the first six weeks. At six weeks the foot is X-rayed, and the patient can transition into supportive shoe wear if radiographic union is present. The patient is referred to physiotherapy for rehabilitation.

\section{Statistics}

The rate of union in our series was compared to similar studies in the published literature using the two-population probability test, or Z-test. 2,4,11-19 To allow for the use of the two-population probability test, only case series were used where the total number of feet and non-unions were reported. The significance level was set at $p<0.05$.

\section{Results}

\section{Population demographics}

Between February 2014 and March 2015, 56 patients had undergone a modified Lapidus procedure to correct a hallux valgus deformity. There were no exclusions from this group. Fifty patients were female and six were male. The average age was 51 years (20-72 years). The average time of follow-up at the time of data collection was 15 months (4-25 months). Three of the patients were smokers. A complete list of comorbidities is presented in Table II. Thirteen patients had bilateral procedures, 16 patients were operated on the right foot and 27 patients were operated on the left. This gave a total of 69 feet for analysis. Of these, three were classified as mild, 38 as moderate and 19 as severe. Four feet $(6 \%)$ were not classified according severity as no preoperative measurements were available. Five patients $(7 \%)$ had the modified Lapidus done as revision surgery for recurrence of the deformity subsequent to previous corrective surgery. One of these patients had a previous modified Lapidus with plate fixation which went onto non-union; this was revised using this crossscrew fixation technique. The other four patients had previous corrective metatarsal osteotomies. Instability of the first ray, as determined clinically by the surgeon according to the method described by Myerson and Badekas, ${ }^{20}$ was the primary indication for the modified Lapidus procedure in 44 feet (64\%). Moderate and severe deformities accounted for $83 \%$ of the cases. Table I shows the percentages in each of these groups. No patients had arthritis of the first tarsometatarsal joint (TMTJ). 
Table II: Comorbidities

\begin{tabular}{|l|c|c|}
\hline \multicolumn{1}{|c|}{ Comorbidity } & $\begin{array}{c}\text { Number of } \\
\text { patients }\end{array}$ & $\begin{array}{c}\text { Number of } \\
\text { feet }\end{array}$ \\
\hline General conditions & 3 & 4 \\
\hline Smokers & 1 & 1 \\
\hline Rheumatoid arthritis & 2 & 1 \\
\hline Scleroderma & 1 & 2 \\
\hline Overweight & 3 & 3 \\
\hline Gout & 1 & 1 \\
\hline Hypothyroid & 2 & 2 \\
\hline Hypertension & 1 & 1 \\
\hline Hypoglycaemia & & 1 \\
\hline Foot conditions & 1 & 2 \\
\hline Cavus foot & 2 & 1 \\
\hline Flatfoot & 1 & 5 \\
\hline Previous foot surgery (excluding & & 4 \\
\hline hallux valgus surgery) & & \\
\hline Previous failed hallux valgus & & \\
\hline surgery (osteotomies) & & \\
\hline
\end{tabular}

Table III: Additional procedures performed

\section{Procedure}

\section{Hallux procedures}

Bunionectomy

64

Removal of hardware from previous correction

3

$\mathrm{MCWC}^{*}$ osteotomy

21

Distal soft tissue release

Akin osteotomy

Bone graft

1

\section{Lesser toe procedures}

\section{Second TMTJ** arthrodesis}

Deformity corrections or neuroma excisions 25

*MCWC: medial closing wedge chevron

**TMTJ: tarsometatarsal joint

Table IV: Complications

\begin{tabular}{|l|c|c|}
\hline \multicolumn{1}{|c|}{ Complication } & Number of feet (n) & (\%) \\
\hline Osseous & 3 & 4 \\
\hline Delayed union & 2 & 3 \\
\hline Non-union & & \\
\hline Deformity & 1 & 1 \\
\hline Recurrence & 2 & 3 \\
\hline Mild residual deformity & 1 & 1 \\
\hline Hyperextension & 1 & 1 \\
\hline Hallux varus (5) & & 1 \\
\hline General & 1 & 1 \\
\hline Pulmonary embolus & 1 & 1 \\
\hline Burning pain & 1 & 1 \\
\hline Intermittent discomfort & & 1 \\
\hline
\end{tabular}

\section{Additional procedures}

Removal of hardware was necessary in three of the revision cases (4\%). MCWC osteotomies were performed in 21 feet $(30 \%)$ and Akin osteotomies in 38 feet (55\%). One revision case, with a non-union from a previous modified Lapidus procedure using plate fixation, required bone grafting (1\%). No other case required bone grafting. Arthrodesis of the second TMTJ was performed in three cases (4\%) with associated degenerative changes of that joint. The 1-2 intermetatarsal joints were not included in the fusion, thus not making this a true Lapidus procedure. Lesser toe surgery was performed in 25 feet (36\%). These are listed in Table III.

\section{Complications}

Complications are listed in Table IV. Two feet had a mild residual valgus deformity. One foot developed a hyperextension deformity, and one foot developed a $5^{\circ}$ hallux varus deformity. These patients were happy with their results and no further surgery was required. No wound complications were reported. One patient described a burning pain after a fall. No fractures were noted, and the pain settled. One patient described intermittent discomfort, which settled after three months.

\section{Union rates}

There were three delayed unions, with incomplete fusion at six weeks. By 12 weeks these three feet had united. Two feet had non-unions that failed to unite within six months. Neither patient required further surgery as the patients became asymptomatic. One of the non-unions occurred in a revision case. The union rate was therefore $97 \%$. Figure 5 shows X-rays demonstrating union.

Table $V$ lists the $z$ scores and $p$ values calculated using the $z$ test to compare union rates between our study and similar studies in the recent literature. ${ }^{2,4,10-19}$ All the other studies reported union rates between 90 and $100 \%$. No study showed a statistically significant difference to our union rate at a significance level of $p<0.05$. Furthermore, no difference was found when the tests were repeated at a significance level of $p<0.01$. Fixation in these studies were mainly solid AO screws, or locked plates with or without lag screws. ${ }^{2,4,10-19}$

\section{Discussion}

The Lapidus procedure has been commonly used for the correction of hallux valgus deformities since being described in 1934. With the ability to correct the deformity in three planes, it a very powerful procedure. $4,8,9$ Indications for its use include hypermobility, generalised ligamentous laxity, and moderate to severe deformities. Its use has been cautioned in smokers and individuals with a shortened first ray. ${ }^{3}$ Previous reports have shown good results with this technique. Kopp et al. reported an improvement of the visual analogue score from 7.2 to $2.3 .{ }^{4} \mathrm{~A}$ successful fusion has also been shown to have a low recurrence rate..$^{10}$

The Lapidus procedure is known to be technically demanding, with its long lever arm. It is this long lever arm that makes the Lapidus a powerful procedure. However, the combination of a long lever arm and a small fusion surface means that it is prone to over and under correction, as well as developing non-unions. ${ }^{3}$ Metaanalysis currently reports non-union rates between 2 and $10 \%{ }^{3}$ In the 14 series that we reviewed, the non-union rate was between 0 and $10 \%$. We had a non-union rate of $3 \%$, which was not found to be statistically different to any of the other 14 studies with the available numbers.

Cadaver studies have shown increased rigidity of lock plate constructs as compared to crossed screws. ${ }^{21-23}$ This has however not translated to superior results in clinical studies, and no good prospective randomised controlled studies exist to validate the superior stability of any of the constructs. ${ }^{2}$ Most studies are retrospective, and the prospective studies have small numbers. 
Table V: Comparisons of union rates

\begin{tabular}{|c|c|c|c|c|c|c|c|}
\hline Study & $\begin{array}{l}\text { No. of feet } \\
\text { (n) }\end{array}$ & $\begin{array}{l}\text { No. of } \\
\text { unions }\end{array}$ & $\begin{array}{l}\text { Union } \\
(\%)\end{array}$ & Fixation used & Bone grafting & z score & $p$ value \\
\hline Current series & 69 & 67 & 97 & Crossed screws (4.7 mm Acutrak®) & One case (revision) & - & - \\
\hline King et al. ${ }^{2}$ & 136 & 133 & 97 & $\begin{array}{l}\text { Crossed screws (AO) (IM screw } \\
\text { added if needed) }\end{array}$ & None & -0.3038 & 0.76418 \\
\hline Kopp et al. ${ }^{4}$ & 38 & 38 & 100 & Crossed screws (AO) & All cases & -1.0594 & 0.28914 \\
\hline De Vries et al. ${ }^{11}$ & 96 & 88 & 92 & $\begin{array}{l}\text { Crossed AO screws (IM }{ }^{\text {a }} \text { screw } \\
\text { added as needed) }\end{array}$ & $\mathrm{DBM}^{\mathrm{b}}$ or $\mathrm{BMA}^{\mathrm{c}}$ & 1.4432 & 0.14986 \\
\hline De Vries et al. ${ }^{11}$ & 47 & 46 & 98 & Lock plate (lag screw as needed) & $\mathrm{DBM}^{\mathrm{b}}$ or $\mathrm{BMA}^{\mathrm{c}}$ & -0.2568 & 0.79486 \\
\hline Gutteck et al. ${ }^{12}$ & 17 & 17 & 100 & Dorsomedial plate & None & -0.7103 & 0.4777 \\
\hline Gutteck et al. ${ }^{12}$ & 17 & 17 & 100 & Plantar plate & None & -0.7103 & 0.4777 \\
\hline Thompson et al. ${ }^{13}$ & 201 & 193 & 96 & Crossed AO screws & All cases & 0.4105 & 0.6818 \\
\hline Popelka et al. ${ }^{14}$ & 143 & 136 & 95 & Variable-in RA & None & 0.6756 & 0.4965 \\
\hline Saxena et al. ${ }^{15}$ & 40 & 39 & 98 & Plate or two distal AO screws & Not mentioned & -0.1226 & 0.90448 \\
\hline Sangeorzan et al. ${ }^{16}$ & 40 & 36 & 90 & Two distal cross AO screws $3.5 \mathrm{~mm}$ & In revision cases & 1.5668 & 0.11642 \\
\hline Mallette et al. ${ }^{17}$ & 36 & 33 & 92 & Staples & None & 1.2413 & 0.21498 \\
\hline Coetzee et al. ${ }^{10}$ & 105 & 98 & 93 & T-configuration screws (AO) $3.5 \mathrm{~mm}$ & None & 1.0979 & 0.27134 \\
\hline Klos et al. ${ }^{18}$ & 59 & 58 & 98 & Plantar plate + lag screw & None & -0.4487 & 0.65272 \\
\hline Ellington et al. ${ }^{19}$ & 25 & 24 & 96 & Crossed screws (AO) & Five cases & 0.2684 & 0.78716 \\
\hline
\end{tabular}

alM: intermetatarsal, ' $\mathrm{DBM}$ : demineralised bone matrix, 'BMA: bone marrow aspirate

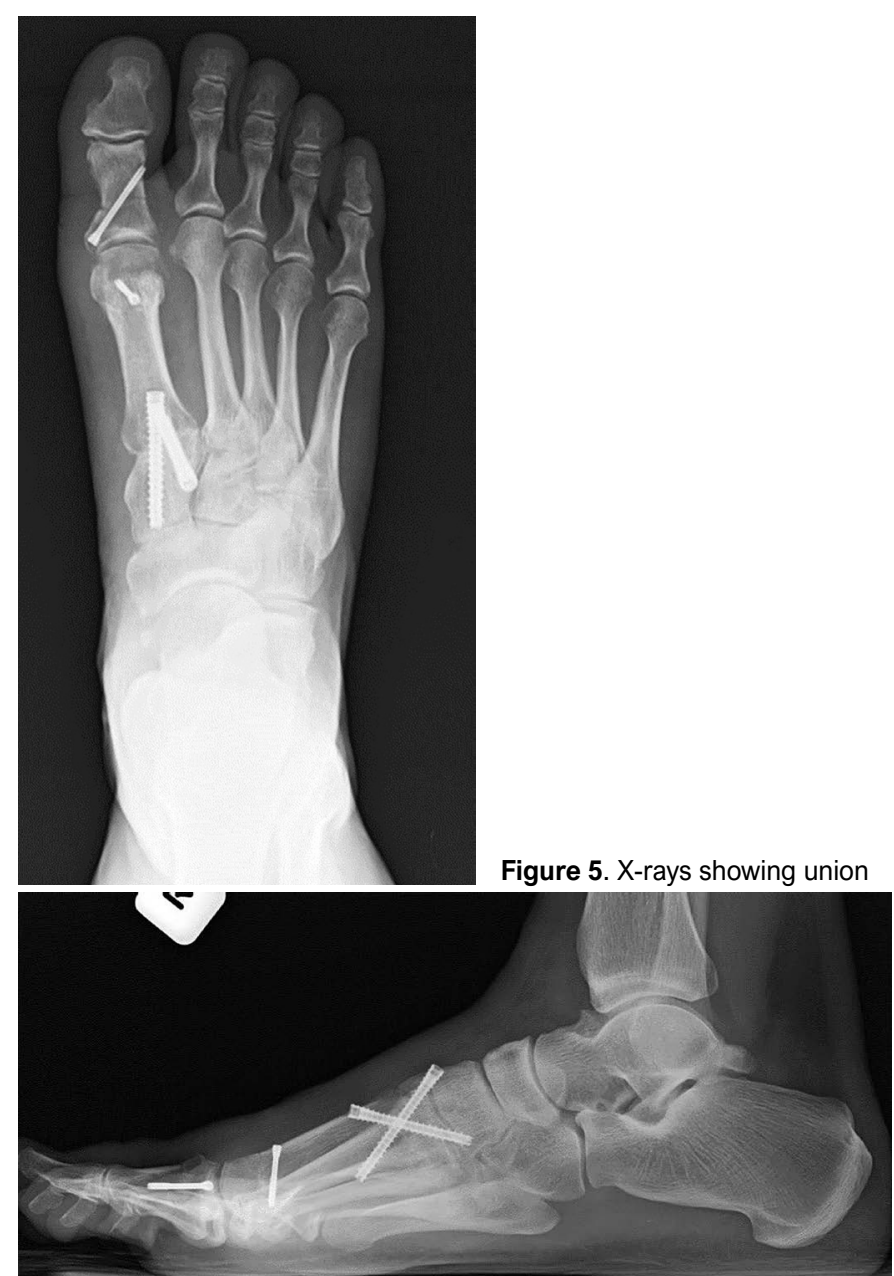

Preparation of the fusion surfaces varied among the different studies. Some authors preferred removal of the subchondral plate, ${ }^{10,15,16}$ whereas others preferred cartilage removal and fenestration of the subchondral plate. ${ }^{7,11,18}$ Ray et al. in a cadaver study showed decreased movement of the screws across the fusion site if the subchondral plate was left intact. ${ }^{24}$ The other area of variability was fixation. Besides various plate constructs, there were also differences in the number of screws (two or three screws) used and the screw configurations with screw fixation techniques. In the two screw fixations, there was a lot of variability in the configuration in which the screws were placed. Coetzee et al. and Sangeorzan et al. placed their screws so as to engage the intermetatarsal joint as well. ${ }^{10,16}$ Some authors using cross-screw configurations, similar to ours, added a third screw to secure the intermetatarsal joint if they felt there was intermetatarsal or intercuneiform instability. All these authors used solid AO 3.0 or 3.5 $\mathrm{mm}$ screws. In our study, we removed the subchondral plate, and used two $4.7 \mathrm{~mm}$ cannulated headless compression screws. We did not find it necessary to include the intermetatarsal or intercuneiform joint in the fusion. The union rates were not found to be statistically different to other studies published in recent literature. However, the cannulated screw system allows for easier placement of screws. The guidewires also help maintain the TMTJ in a reduced position so that adequate correction can be confirmed on imaging prior to definitive fixation. Solid AO screws have a head which can result in hardware prominence requiring a subsequent procedure to remove the hardware. Some surgeons avoid this by countersinking the head of the screw. This can sometimes compromise the dorsal cortex when tightening the screw to compress the joint, by cracking the dorsal rim, thereby losing stability and even reduction. The screws we use are headless, thus avoiding these complications.

King et al. suggested that a non-weight-bearing status postoperatively is a risk for non-union and early pedal loading reduces disuse osteopaenia, limits muscle atrophy and facilitates rehabilitation. ${ }^{2}$ The trend in the recent literature is towards early weight bearing post-operatively. Our patients were encouraged to start weight bearing immediately in heel wedge shoes, as tolerated.

Interestingly, we had one patient who complained of intermittent discomfort, despite having united. The only other publication 
to report this was Kopp et al. ${ }^{4}$ They reported $24 \%$ midfoot and $34 \%$ forefoot discomfort after the Lapidus procedure. No further intervention was needed for these patients.

Limitations of this study is that it was performed retrospectively and lacks outcome measurements for patient satisfaction and postoperative corrections achieved. This should be added in any future prospective studies.

\section{Conclusion}

The modified Lapidus procedure is a powerful procedure for the correction of hallux valgus. However, it is technically demanding and prone to developing non-unions. Attention to detail is imperative to prevent this. We present a technique where meticulous joint preparation and fixation with two $4.7 \mathrm{~mm}$ headless compression cross-screws has given a $97 \%$ union rate. This was not statistically different from published data where a locking plate or solid screws were used. Being headless they minimise hardware prominence and intra-operative fractures. Early weight bearing is possible and beneficial with this technique.

\section{Ethics statement}

This was a retrospective study. Formal consent was not required for the study. Al procedures performed in this study were in accordance with the ethical standards of the institution and with the 1964 Helsinki declaration and its later amendments or comparable ethical standards.

\section{Declaration}

The authors declare authorship of this article and that they have followed sound scientific research practice. This research is original and does not transgress plagiarism policies.

\section{Author contributions}

ZM contributed to study idea and design, data collection and processing, and write-up of proposal and study at all stages. PF contributed to the study design, and write-up of the study at all stages. NS contributed to the study idea and design, and write-up of the study.

\section{ORCID}

Z Mayet ii http://orcid.org/0000-0002-7340-3148

PNF Ferrao (iD http://orcid.org/0000-0003-4639-0326

NP Saragas (iD http://orcid.org/0000-0002-5566-7588

\section{References}

1. Lapidus PW. Operative correction of the metatarsus varus primus in hallux valgus. Surg Gynecol Obstet. 1934;58:183-91.

2. King CM, Richey J, Patel S, Collman DR. Modified Lapidus with crossed screw fixation: Early weightbearing in 136 patients. J Foot Ankle Surg 2015;54:69-75.

3. Schmid T, Krause F. The modified Lapidus procedure. Foot Ankle Clin 2014;19:223-33.

4. Kopp FJ, Patel MM, Levine DS, Deland JT. The modified Lapidus procedure for hallux valgus: A clinical and Radiographic Analysis. Foot Ankle Int 2005;26(11):913-17.

5. Bednarz PA, Manoli A. Modified Lapidus for the treatment of hypermobile hallux valgus. Foot Ankle Int 2000;21(10):816-21.

6. Taylor GN, Metcalfe SA. A review of surgical outcomes of the Lapidus procedure for the treatment of hallux abductovalgus and degenerative joint disease of the first MCJ. Foot 2008;18:206-10.

7. Ellington JK, Myerson MS, Coetzee JC, Stone RM. The use of the Lapidus procedure for recurrent hallux valgus. Foot Ankle Int 2011;32(7):674-80.

8. Toolan BC. Surgical strategies: The Lapidus procedure. Foot Ankle Int 2007;28(10):1108-14.

9. Baravarian B, Ben-Ad R. Contemporary approaches and advancements to the Lapidus procedure. Clin Podiatr Med Surg 2014;31:299-308.

10. Coetzee JC, Wickum D. The Lapidus procedure: A prospective cohort outcome study. Foot Ankle Int 2004;25(8):526-31.
11. De Vries JG, Granata JD, Hyer CF. Fixation of the first tarsometatarsal arthrodesis: A retrospective comparative cohort of two techniques. Foot Ankle Int 2011;32(2):158-62.

12. Gutteck N, Wohlrab D, Zeh A, Radetzki F, Delank K-S, Lebek S. Comparative study of Lapidus bunionectomy using different osteosynthesis methods. Foot Ankle Surg 2013;19:218-21.

13. Thompson IM, Bohay DR, Anderson JG. Fusion rate of first tarsometatarsal arthrodesis in the modified Lapidus procedure and flatfoot reconstruction. Foot Ankle Int 2005;26(9):698-703.

14. Popelka S, Hromảdka R, Vavřik P, Bartảk V, Popelka S Jr., Sosna A. Hypermobility of the first metatarsal bone in patients with Rheumatoid arthritis treated by Lapidus procedure. BMC Musculoskelet Disord 2012;13:148-55.

15. Saxena A, Nguyen A, Nelsen E. Lapidus bunionectomy: Early evaluation of crossed lag screws versus locking plate with plantar lag screw. J Foot Ankle Surg 2009;48(2):170-79.

16. Sangeorzan B, Hansen ST Jr. Modified Lapidus procedure for hallux valgus. Foot Ankle Int 1989;9(6):262-66.

17. Mallete JP, Glenn CL, Glod DJ. The incidence of non-union after Lapidus arthrodesis using staple fixation. J Foot Ankle Surg 2014;53:303-306.

18. Klos TK, Wilde $\mathrm{CH}$, Lange A, Wagner A, Gras F, Skulev HK, Muckley T, Simons P. Modified Lapidus arthrodesis with plantar plate and compression screw for treatment of hallux valgus with hypermobility of the first ray: A preliminary report. Foot Ankle Surg 2013;19:239-44.

19. Ellington JK, Myerson MS, Coetzee JC, Stone RM. The use of the Lapidus procedure for recurrent hallux valgus. Foot Ankle Int 2011;32(7):674-80.

20. Myerson MS, Badekas A. Hypermobility of the first ray. Foot Ankle Clin 2000;5(3):469-84

21. Young NJ, Zelen CM. New fixation techniques and alternative fixation for the Lapidus arthrodesis. Clin Podiatr Med Surg 2013;304:23-434.

22. Scranton PE, Coetzee JC, Carreira D. Arthrodesis of the first metatarsocuneiform joint: A comparative study of fixation methods. Foot Ankle Int 2009;30(4):341-45

23. Klos K, Gueorguiev B, Mückley T, Fröber R, Hofmann GO, Schwieger K, Windolf M. Stability of medial locking plate and compression screw versus two crossed screws for Lapidus arthrodesis. Foot Ankle Int 2010;31(2):158-63.

24. Ray RG, Ching RP, Christensen JC, Hansen ST Jr. Biomechanical analysis of the first metatarsocuneiform arthrodesis. J Foot Ankle Surg 1998;37(5):376-85. 